\title{
Thermoneutrality improves skeletal impairment in adult Prader-Willi syndrome mice
}

\author{
Thomas M Braxton'1, Dionne E A Sarpong'1, Janine L Dovey'1, Anne Guillou², Bronwen A J Evans³, Juan M Castellano4, \\ Bethany E Keenann, Saja Baraghithy ${ }^{6}$, Sam L Evans ${ }^{5}$, Manuel Tena-Sempere ${ }^{4,7}$, Patrice Mollard ${ }^{2}$, Joseph Tam ${ }^{6}$ and $^{4}$ \\ Timothy Wells 1
}

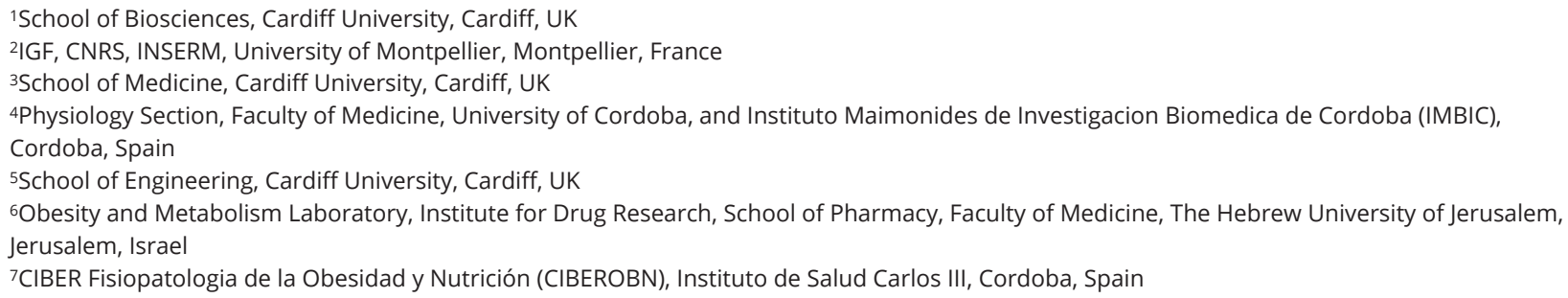

Correspondence should be addressed to T Wells: wellst@cardiff.ac.uk

\begin{abstract}
Human Prader-Willi syndrome (PWS) is characterised by impairments of multiple systems including the growth hormone $(\mathrm{GH})$ axis and skeletal growth. To address our lack of knowledge of the influence of PWS on skeletal integrity in mice, we have characterised the endocrine and skeletal phenotype of the PWS-ICdel mouse model for 'full' PWS and determined the impact of thermoneutrality. Tibial length, epiphyseal plate width and marrow adiposity were reduced by 6,18 and 79\% in male PWS-ICdel mice, with osteoclast density being unaffected. Similar reductions in femoral length accompanied a $32 \%$ reduction in mid-diaphyseal cortical diameter. Distal femoral Tb.N was reduced by $62 \%$, with individual trabeculae being less plate-like and the lattice being more fragmented (Tb.Pf increased by $63 \%$ ). Cortical strength (ultimate moment) was reduced by $26 \%$ as a result of reductions in calcified tissue strength and the geometric contribution. GH and prolactin contents in PWS-ICdel pituitaries were reduced in proportion to their smaller pituitary size, with circulating IGF-1 concentration reduced by $37-47 \%$. Conversely, while pituitary luteinising hormone content was halved, circulating gonadotropin concentrations were unaffected. Although longitudinal growth, marrow adiposity and femoral geometry were unaffected by thermoneutrality, strengthened calcified tissue reversed the weakened cortex of PWS-ICdel femora. While underactivity of the GH axis may be due to loss of Snord116 expression and impaired limb bone geometry and strength due to loss of Magel2 expression, comprehensive analysis of skeletal integrity in the single gene deletion models is required. Our data imply that thermoneutrality may ameliorate the elevated fracture risk associated with PWS.
\end{abstract}

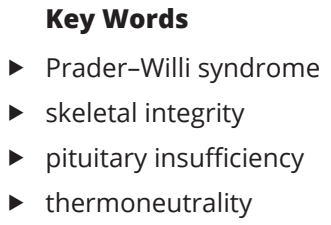

Journal of Endocrinology (2019) 243, 175-186 


\section{Introduction}

Prader-Willi syndrome (PWS) is a neurodevelopmental disorder arising from the loss of expression of one or more genes from the paternal allele of the PWS locus (Butler et al. 2016). The PWS phenotype is complex, characterised by neonatal hypotonia and an initial failure to thrive (Miller et al. 2011), the subsequent development of hyperphagia (Miller et al. 2011), hyperghrelinaemia (Cummings et al. 2002), and growth hormone (GH) deficiency (Grosso et al. 1998), resulting in severe truncal obesity and growth retardation (Kahn et al. 2018).

By manipulating the murine PWS locus on chromosome 7, several mouse models for this condition have linked the contribution of individual PWS genes to specific phenotypic characteristics. For example, while loss of the MAGE-family gene, Necdin has no effect on growth or adiposity (Cattanach et al. 1992, Muscatelli et al. 2000) Necdin-null mice display enhanced differentiation and/or proliferation of astrocytes (Fujimoto et al. 2016), neocortical neural precursor cells (Minamide et al. 2014), haematopoietic stem cells (Asai et al. 2012) and preadipocytes (Fujiwara et al. 2012). Similarly, although deletion of another MAGE-family gene, Magel2, fails to induce hyperphagia with standard diets (Bischof et al. 2007), Magel2-null mice display impaired GH axis function (Tennese \& Wevrick 2011) and leptin sensitivity (Pravdivyi et al. 2015), accompanied by a doubling of fat mass (Bischof et al. 2007). In contrast, loss of the small nucleolar (sno)RNA, Snord116, results in mild hyperphagia and impaired meal termination, but accompanied by intra-abdominal leanness (Ding et al. 2008).

Such studies have revealed features of PWS not commonly reported in humans. For example, our study of metabolic homeostasis in the PWS-ICdel mouse, in which paternal inheritance of an imprinting centre (IC) deletion results in a complete lack of gene expression from the entire PWS interval (Chamberlain et al. 2004), revealed overactive brown fat and excess heat production (Golding et al. 2017). Unlike humans with PWS (Kahn et al. 2018), PWS-ICdel mice display profound abdominal leanness, probably resulting from a compromised capacity of PWS adipocytes to import lipid (Golding et al. 2017), a phenomenon reported in isolated human PWS adipocytes (Cadoudal et al. 2014).

Disruption of adipocyte function has extra-metabolic consequences. For example, there is a bi-directional relationship between fat and bone (Leiben et al. 2009), with bone marrow adipocytes and the bone-forming osteoblasts arising from the same mesenchymal stem cells (MSCs)
(Beresford et al. 1992, Di Iorgi et al. 2008) and osteogenesis being influenced by leptin (Thomas et al. 1999, Hamrick et al. 2005, Evans et al. 2011). Although several studies have examined the effects of the loss of specific PWS interval regions/genes on bone (Kamaludin et al. 2016, Khor et al. 2016, Baraghithy et al. 2019), a study of the impact of losing all of the genes in the PWS locus is lacking. We have therefore conducted a study of the growth, morphology, microarchitecture and biomechanical properties of the appendicular bones of PWS-IC ${ }^{\text {del }}$ mice and characterised the underlying endocrine phenotype. In addition, since we have recently shown that maintaining PWS-ICdel mice at thermoneutrality may reduce proportionate hyperphagia (Golding et al. 2017), we quantified the effect of this manipulation on bone morphology and strength.

\section{Materials and methods}

\section{Animals}

The mice used in this study were bred under the authority of the Animals (scientific procedures) Act 1986 (UK), with subsequent procedures conforming with the ARRIVE guidelines and specifically approved by the Cardiff University Animal Welfare Ethical Review Body (AWERB).

PWS-IC ${ }^{m+/ p-}$ (referred to throughout as PWS-ICdel) and WT littermates were generated by crossing ICdel-positive males with WT females. Given that PWS-IC ${ }^{d e l}$ animals on a pure C57BL/6J background suffer severe postnatal lethality (Yang et al. 1998), we crossed IC ${ }^{\text {del-positive males }}$ with CD1 females and selectively culled WT littermates (identified on the basis of their increased size $48 \mathrm{~h}$ after birth) leaving only 1 or 2 WT pups per litter (Chamberlain et al. 2004). Animals were weaned at approximately 4 weeks of age and housed in single-sex groups with WT littermates (2-5 animals per cage).

All animals were maintained on a $12 \mathrm{~h}$ light/darkness cycle (lights on 07:00 h) at $20-22^{\circ} \mathrm{C}$ (unless otherwise stated), with ad libitum access to water and standard laboratory chow (Rat and Mouse No. 3 Breeding Diet, Special Diet Services Ltd., Witham, Essex, UK) containing $4.2 \%$ crude fat; $22.4 \%$ crude protein; $4.2 \%$ crude fibre; $7.6 \%$ crude ash (see Tilston et al. 2019 for full dietary composition).

\section{Study 1. Tibial growth and marrow adiposity in PWS-ICdel mice}

After an overnight fast (with water available ad libitum), 18-month-old male PWS-ICdel and WT littermates were https://joe.bioscientifica.com https://doi.org/10.1530/JOE-19-0279 (c) 2019 Society for Endocrinology Published by Bioscientifica Ltd.
Printed in Great Britain 
killed by cervical dislocation. Left tibiae were excised, the length determined with a hand-held micrometre and fixed in buffered formal saline for $48 \mathrm{~h}$ at $4^{\circ} \mathrm{C}$ before being decalcified in $0.5 \mathrm{M}$ EDTA ( $\mathrm{pH}$ 7.6). Tibiae were stored in $70 \%$ ethanol at $4^{\circ} \mathrm{C}$ prior to quantifying epiphyseal plate width (EPW), marrow adiposity and osteoclast number (see below).

\section{Study 2. Femoral phenotype in PWS-IC del mice}

Left femora were excised from the mice in study 1 ; soft was tissue removed and length was measured with a handheld micrometre. Femora were wrapped in saline-soaked gauze, snap frozen and stored at $-80^{\circ} \mathrm{C}$ for subsequent $\mu$-CT and biomechanical analysis (see below).

\section{Study 3. Endocrine status in PWS-ICdel mice}

Male and female PWS-ICdel and their 6-15-month-old WT littermates were anaesthetised with isoflurane and killed by decapitation. Pituitaries were dissected, weighed, snap frozen and stored at $-80^{\circ} \mathrm{C}$ for subsequent quantification of $\mathrm{GH}$, prolactin (PRL) and luteinising hormone (LH) content (see below).

Male and female PWS-ICdel and their 5-9-month-old WT littermates were anaesthetised with isoflurane and killed by decapitation. Pituitaries were dissected and weighed and trunk blood collected into EDTA-coated tubes, vortexed and centrifuged. Aliquots of separated plasma were snap frozen and stored at $-80^{\circ} \mathrm{C}$ for subsequent quantification of circulating insulin-like growth factor-1 (IGF-1), LH and follicle-stimulating hormone (FSH) (see below).

\section{Study 4. The effect of thermoneutrality on skeletal parameters in PWS-ICdel mice}

Male and female PWS-ICdel and their 6-15-month-old WT littermates were group-housed in standard mouse cages (2-3 mice/cage) at $20-22^{\circ} \mathrm{C}$ or at thermoneutrality $\left(30^{\circ} \mathrm{C}\right)$ (Golding et al. 2017). After 9 weeks, mice were anaesthetised with isoflurane and killed by decapitation. Tibiae and femora were excised and processed as above (studies 1 and 2) for subsequent quantification of growth, adiposity, geometry and strength.

\section{Quantification of tibial epiphyseal plate width and marrow adiposity}

Tibial EPWs and marrow adiposity were measured as previously described (Gevers etal.2002, Thompson etal.2004,

(c) 2019 Society for Endocrinology Published by Bioscientifica Ltd. Printed in Great Britain
Navein et al. 2016, Hopkins et al. 2017). In brief, three $7 \mu \mathrm{m}$ anterior-posterior longitudinal tibial sections were stained with Masson's Trichrome and visualised under light microscopy. Total plate width was measured in triplicate on digitally captured images of each section using the interactive feature tool of Leica QWin (V3.2). Marrow adiposity was quantified on digital images of mid-diaphyseal marrow and photomicrographs analysed with National Institutes of Health (NIH) ImageJ, to quantify \%adiposity, and the number and size of marrow adipocytes.

\section{Quantification of tibial osteoclasts}

To identify osteoclasts, consecutive paraffin sections were de-parraffinised, stained for tartrate-resistant acid phosphatase (TRAP; Sigma-Aldrich), and counterstained with Mayer's haematoxylin. Histomorphometric analysis was performed on digital photomicrographs using IMAGE-PRO PLUS V.6 (Media Cybernetics, Silver Spring, $\mathrm{MD}$, USA) to determine the number of $\mathrm{TRAP}^{+}$osteoclasts per bone surface (N.Oc/BS).

\section{Quantification of femoral trabecular architecture}

The trabecular microarchitecture of the distal femora was assessed using a high-resolution $\mu$-CT system (Bruker Skyscan 1272, Kontich, Belgium) as previously described in rats (Evans et al. 2011) and mice (Navein et al. 2016). Femora were thawed, mounted on the sample presentation stage and orientated by taking a series of single images. Scanning was conducted at $70 \mathrm{kV}$ and $142 \mu \mathrm{A}$, using a resolution of $9.04 \mu \mathrm{m}, 990$ millisecond exposures, a rotation step of $0.60^{\circ}$ and a $0.5 \mathrm{~mm}$ aluminium filter. Analysis was performed according to the ASBMR guidelines (Bouxsein et al. 2010). In brief, a $1 \mathrm{~mm}^{3}$ ROI of secondary spongiosa $0.5 \mathrm{~mm}$ above the centre of the distal epiphyseal plate was analysed using the CT image analysis software (CT-An; https://www.bruker.com/ products/microtomography/micro-ct-software/3dsuite. html). Trabecular bone was separated from cortical bone within the area of interest by using the freehand drawing tool in CT-An. After scanning, femora were re-wrapped in saline-soaked gauze and re-frozen for strength testing.

\section{Biomechanical testing}

Mechanical strength of the femoral cortex was quantified by three-point bending as previously described (Stevenson et al. 2009, Navein et al. 2016), with the lower rollers set 
at 6.42 and $4.04 \mathrm{~mm}$ apart for WT and PWS-ICdel femora respectively and the central roller positioned equidistant from the lower rollers over the thinnest part of the middiaphyseal region, to give an approximately posterior load direction. Femora were loaded at a crosshead speed of $2 \mathrm{~mm} / \mathrm{min}$ until failure, with load and displacement data recorded by a Zwick Z050 tensile testing machine fitted with a $1 \mathrm{kN}$ load cell (Zwick Testing Machines Ltd., Leominster, Herefordshire, UK). Ultimate tensile stress was calculated using failure load, morphometric measurements of cortical wall thicknesses and diameter (taken from cross-sectional $\mu$-CT images corresponding to the fracture site as determined by measuring the distance from the end of the femur to the fracture point using a hand-held micrometre) and simple beam theory.

\section{Hormone quantification}

Pituitaries were homogenised in $0.5 \mathrm{~mL}$ lysis buffer (Tris $0.1 \mathrm{M} \mathrm{pH}$ 7.4, NaCl 0.15 M, EGTA $1 \mathrm{mM}$, EDTA $1 \mathrm{mM}$, Triton $1 \%$, protease inhibitor cocktail (Sigma-Aldrich, P8340) and phosphatase inhibitor cocktail 3 (Sigma-Aldrich, P0044)), maintained on ice for $30 \mathrm{~min}$ and centrifuged for $10 \mathrm{~min}$ at $13,000 \mathrm{~g}$. Protein concentration was measured in a 1:100 dilution of $4 \mu \mathrm{L}$ of the supernatant with the QuantiPro BCA assay kit (Sigma-Aldrich, QPBCA-1KT) using protein standards (Sigma-Aldrich, P0914). Samples were diluted in PBS to normalise protein concentration. GH, LH and PRL levels were measured using sandwich ELISAs (Steyn et al. 2011, 2013, Guillou et al. 2015).

Plasma IGF-1 concentrations were determined in duplicate using a rat/mouse total IGF-1 immunoenzymometric assay (OCTEIA ${ }^{\circledR}$ Immunodiagnostic Systems Ltd., \#AC-18F1) according to the manufacturer's instructions, with samples pre-treated to avoid binding protein interference. LH and FSH levels were measured in plasma samples using radioimmunoassay reagents provided by the National Institutes of Health (Dr A F Parlow, Torrance, CA, USA). Rat LH-I-10 and FSH-I-9 were labelled with ${ }^{125}$ I by the chloramine-T method, and LH and FSH concentrations expressed using reference preparations LH-RP-3 and FSH-RP-2 as standards. Intra- and inter-assay coefficients of variation were $<8$ and $<10 \%$ for $\mathrm{LH}$ and $<6$ and $<9 \%$ for FSH, respectively. Assay sensitivities were $5 \mathrm{pg} /$ tube for $\mathrm{LH}$ and $20 \mathrm{pg} /$ tube for FSH.

\section{Statistical analyses}

Results are expressed as mean \pm S.E.M., and compared by unpaired Student's $t$-test or one-way ANOVA and Bonferroni's selected pairs post hoc test (using GraphPad Prism, GraphPad Software Inc.), as indicated in the figure legends, with $P<0.05$ considered significantly different.

\section{Results}

\section{Study 1. Tibial growth and marrow adiposity in PWS-ICdel mice}

Tibial length and EPW were reduced in PWS-ICdel males by $6 \%(P<0.001$; Fig. $1 \mathrm{~A})$ and $18 \%(P<0.01$; Fig. $1 \mathrm{~B})$ respectively. A profound (79\%) reduction in tibial marrow adiposity $(P<0.05$; Fig. $1 \mathrm{C}$ and inset pictures a and $\mathrm{b})$ was due to a combination of a $53 \%$ reduction in marrow adipocyte number $(P<0.05$; Fig. $1 D)$ and a $48 \%$ reduction in mean adipocyte size $(P<0.05$; Fig. $1 \mathrm{E})$. Adipocyte size profiling (Fig. 1F) revealed a loss of larger adipocytes, especially those $>825 \mu^{2}(P<0.05)$.

Analysis of TRAP+-stained sections revealed a $62 \%$ reduction in tibial osteoclast number $(P<0.05$; data not shown), but when corrected for the $65 \%$ reduction in tibial trabecular surface $(P<0.05$; data not shown), the osteoclast density was unaffected $(P=0.403$; Fig. $1 G)$.

\section{Study 2. Femoral phenotype in PWS-ICdel mice}

A $4 \%$ reduction in femoral length in PWS-IC ${ }^{\text {del }}$ mice $(P<0.05$; Fig. $2 \mathrm{~A})$ was accompanied by a $32 \%$ reduction in cortical (anterior-posterior) diameter $(P<0.05$; Fig. 2B) with mean cortical wall thickness in PWS-IC $d e l$ mice being $73 \%$ of that in WT littermates ( $P=0.055$; Fig. $2 \mathrm{C}$ ). $\mu \mathrm{CT}$ analysis revealed that trabecular number (Tb.N) in the distal femora of PWS-ICdel mice was reduced by $62 \%(P<0.01$; Fig. 2D). Although the overall trabecular thickness (Tb.Th) was unaffected $(P=0.110$; Fig. 2E), the cross-sectional shape became more cylindrical (less platelike) in PWS-ICdel mice (structural modal index (SMI) increased by $25 \%$; $P<0.05$; Fig. $2 \mathrm{~F}$ ). Trabecular surface was reduced in PWS-ICdel femora by $72 \%(P=0.0006$; data not shown), but when corrected for the $77 \%$ reduction in trabecular volume ( $P=0.0009$; data not shown), relative trabecular surface $(\mathrm{BS} / \mathrm{BV})$ was increased by $29 \%(P<0.01$; Fig. 2G). These changes were accompanied by an $18 \%$ increase in trabecular separation (Tb.Sp; $P<0.01$; Fig. $2 \mathrm{H})$ and a marked fragmentation of the trabecular lattice (63\% increase in pattern factor (Tb.Pf; $P<0.05$; Fig. 2I)). Although mean degree of anisotropy in PWS-ICdel mice was $125 \%$ of that in WT littermates, this index of trabecular 
C Tibial Adiposity
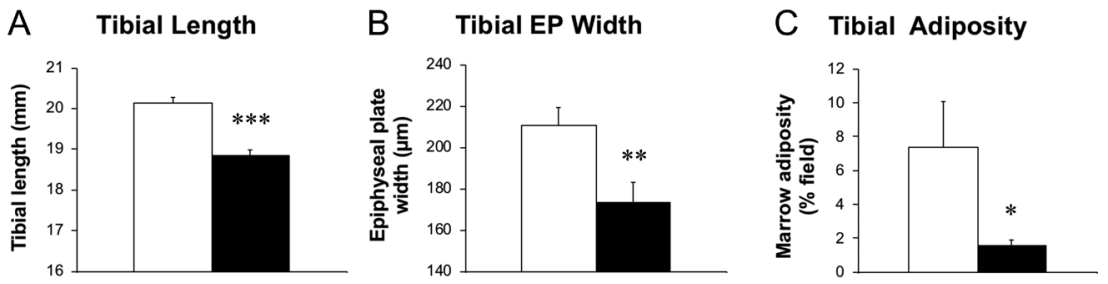

D Adipocyte Number
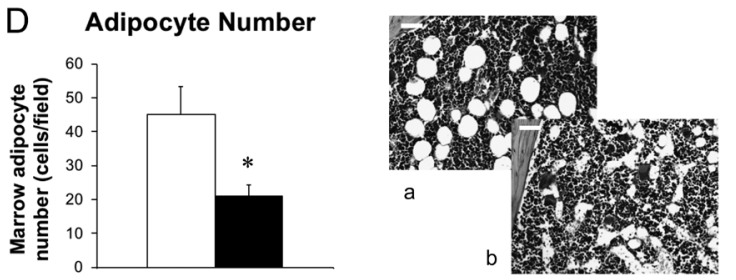

\section{E Adipocyte Size}

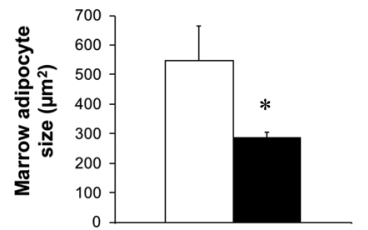

G Osteoclast Density

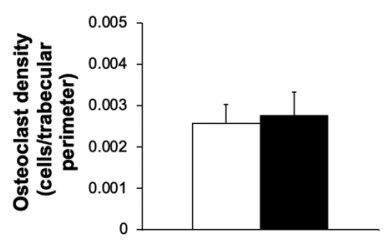

$\square$ WT

PWS-IC del

\section{Figure 1}

PWS-ICdel mice show impaired tibial growth and adiposity. (A) Quantification of tibial length in 18-month-old male WT and PWS-ICdel littermate mice. Tibial epiphysial plate (EP) width (B) was quantified in Masson's Trichrome-stained sections and tibial marrow adiposity (C), marrow adipocyte number (D), size (E) and size profile (F) quantified in digital images of Toluidene blue-stained sections from WT (a) and PWS-IC ${ }^{\text {del }}$ (b) littermates. Osteoclast density $(\mathrm{G})$ was quantified in TRAP+-stained sections. Data shown are mean \pm S.E.M. ( $n=6$ for both genotypes), with statistical comparisons performed by Student's unpaired $t$-test $(* P<0.05 ; * * P<0.01 ; * \star * P<0.001$ vs WT littermates). orientation was not significantly different $(P=0.098$; data not shown).

Biomechanical strength of PWS-IC ${ }^{\text {del }}$ femoral cortex was reduced by $26 \%$ (ultimate moment; $P<0.05$; Fig. $3 \mathrm{~A}$ ).
This was due to an $80 \%$ decrease in the geometric contribution to strength (second moment of area; $P<0.05$; Fig. 3C), the strength of the calcified tissue (ultimate tensile stress (UTS)) being increased by 65\% (P<0.05; Fig. 3B).

\section{A Femoral Length}

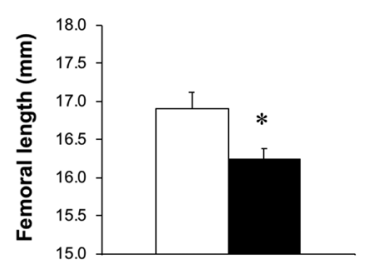

D Trabecular Number

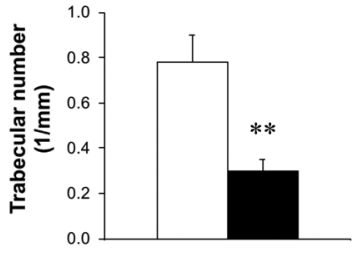

G Trabecular Surface

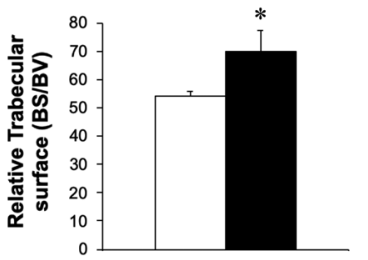

B Cortical Diameter

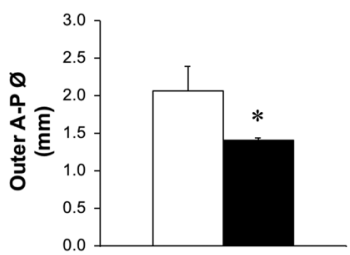

E Trabecular Thickness

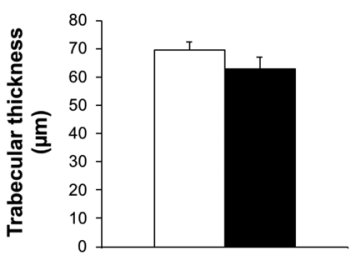

H Trabecular Separation

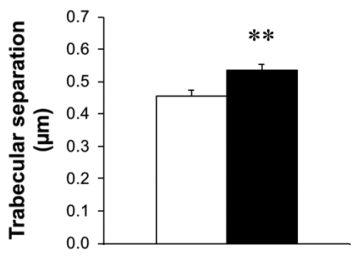

WT

PWS-IC del

\section{Wall Thickness}

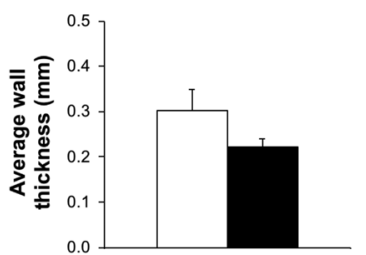

\section{F Trabecular Shape}

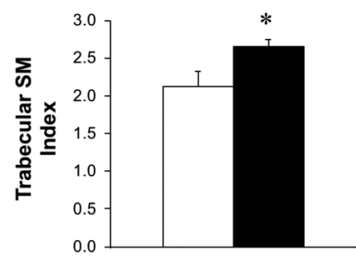

I Lattice Fragmentation

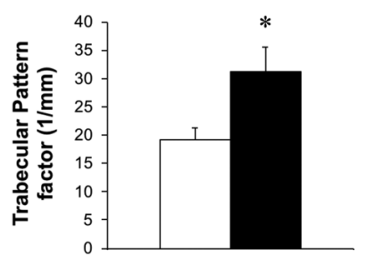

Figure 2

PWS-ICdel mice show impaired femoral morphology. Measurement of femoral length (A), outer cortical (anterior-posterior) diameter (A-P Ø; $B$ ) and average cortical wall thickness (C) in 18-month-old male WT ( $n=6$ ( 3 for B and C)) and PWS-IC del $(n=6)$ littermate mice. $\mu$-CT was used to quantify the number (Tb.N; D), thickness (Tb.Th; E), cross-sectional shape (structural modal (SM) index; F), relative surface (BS/BV; G), separation (Tb.Sp; $\mathrm{H}$ ) and lattice fragmentation (Pattern factor; I) of trabeculae in the distal femora. Data shown are mean \pm S.E.M., with statistical comparisons performed by Student's unpaired $t$-test ( $* P<0.05 ; * * P<0.01$ vs WT littermates). 

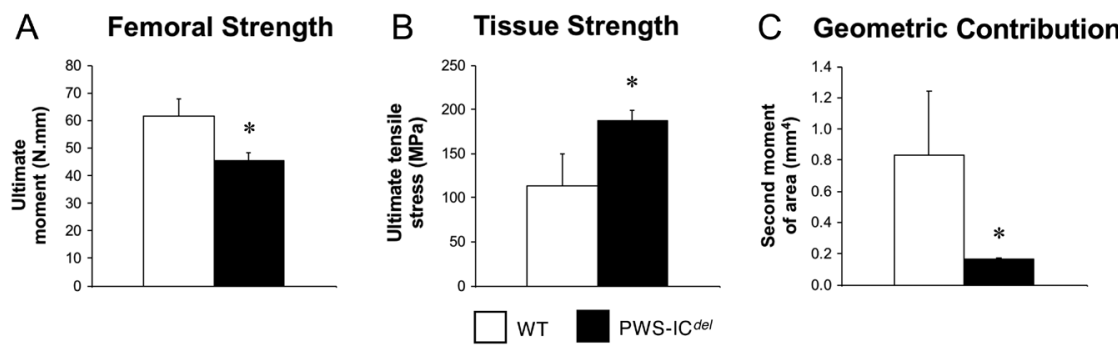

Figure 3

PWS-ICdel mice show compromised femoral strength. Measurement of femoral strength (ultimate moment; A), tissue strength (ultimate tensile stress; B) and the geometric contribution to strength (second moment of area; $C$ ) in 18-month-old male WT ( $n=6$ ( 3 for B and C)) and PWS-IC ${ }^{d e l}(n=6)$ littermate mice. Data shown are mean \pm S.E.M., with statistical comparisons performed by Student's unpaired $t$-test $(* P<0.05$ vs WT littermates).

\section{Study 3. Endocrine status in PWS-ICdel mice}

To investigate whether skeletal impairment might be due to endocrine dysfunction, we quantified pituitary and circulating hormone concentrations. Although not sexually dimorphic in either WT or PWS-ICdel mice, pituitary weight was reduced in both male and female PWS-ICdel mice by 35 and $43 \%$ respectively $(P<0.01$ and $P<0.001$; Fig. 4A). Similarly, pituitary GH content was reduced by 42 and $56 \%$ in male and female PWS-ICdel mice $(P<0.05$; Fig. $4 \mathrm{~B})$ in proportion to protein content (data not shown). While average pituitary PRL content in male PWS-ICdel mice was only $45 \%$ of that in WT males, this was not significantly different $(P>0.05)$. In contrast, female PWS-ICdel mice showed a $41 \%$ reduction in PRL content $(P<0.05$; Fig. 4C); the marked sexual dimorphism seen in WT mice $(P<0.0001)$ being retained in PWS-IC ${ }^{d e l}$ littermates $(P<0.01$; Fig. 4C). This sexual dimorphism $(P<0.0001)$, but not PRL deficiency, was retained when PRL contents were corrected for protein content (data not shown). Male PWS-IC ${ }^{d e l}$ mice showed a marked $(58 \%)$ reduction in pituitary LH content $(P<0.0001$; Fig. 4D), but while mean LH content in female PWS-ICdel mice was only $54 \%$ of that in WT females, this was not significantly different $(P=0.535$; Fig. 4D). In addition, the marked sexual dimorphism in LH content seen in WT mice $(P<0.0001)$ was not replicated in PWS-IC ${ }^{d e l}$ littermates $(P=0.412)$. These differences in $\mathrm{LH}$ content remained after correction for protein content $(P<0.05$; data not shown).

Circulating IGF-1 was reduced in male and female PWS-IC ${ }^{d e l}$ mice by 47 and 37\% respectively $(P<0.0001$ and $P<0.001$; Fig. 5B). Although mean plasma $\mathrm{LH}$ and FSH concentration in PWS-ICdel males were 163 and $123 \%$ of that in male WT littermates, these were not significantly different ( $P>0.900$; Fig. 5C and D). Plasma $\mathrm{LH}$ and FSH concentrations were comparable in WT and PWS-ICdel females, and there was no sexual dimorphism in circulating gonadotrophin levels in either genotype (Fig. 5C and D).

\section{Study 4. The effect of thermoneutrality on skeletal parameters in PWS-ICdel mice}

As in study 1, tibial length in male PWS-ICdel mice at standard ambient temperature was reduced by $11 \%$ $(P<0.0001$; Fig. 6A), with a similar $(10 \%)$ reduction in females $(P<0.0001$; data not shown). This difference was maintained at thermoneutrality in males (9\% reduction; $P<0.001$; Fig. 6A) and females (8\% reduction; $P<0.0001)$, thermoneutrality having no effect on either tibial length or EPW in either genotype (Fig. 6A and B).

Mean tibial marrow adiposity and adipocyte number in PWS-IC ${ }^{d e l}$ mice at standard ambient temperature were only 22 and $29 \%$ of that in WT males, but given the variation in the WT data, these were not statistically different ( $P=0.5668$ (adiposity); Fig. 6C; $P=0.3388$ (adipocyte number); Fig. 6D). Thermoneutrality had no statistically
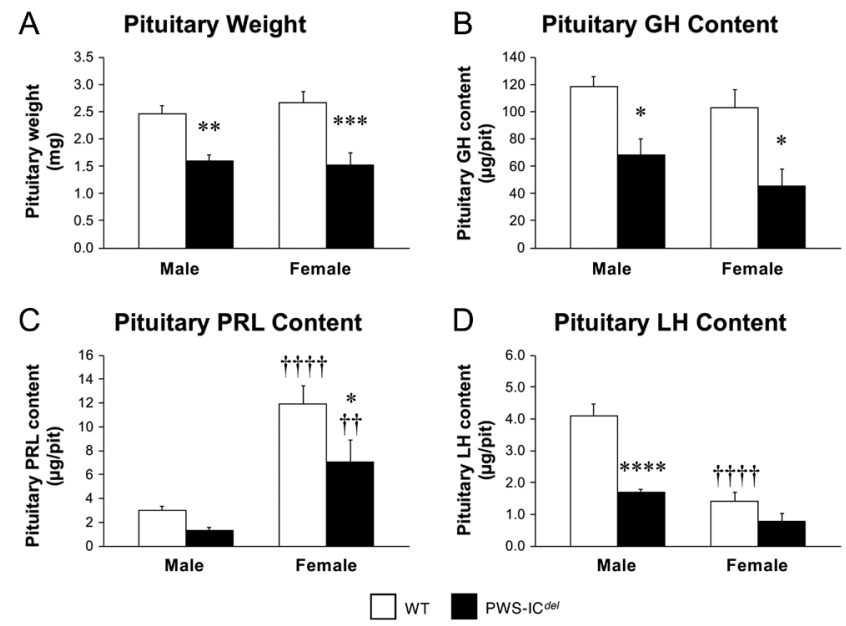

\section{Figure 4}

PWS-ICdel mice show multiple pituitary hormone deficiencies. Quantification of pituitary weight $(A)$ and growth hormone $(\mathrm{GH} ; \mathrm{B})$, prolactin (PRL; C) and luteinising hormone ( $\mathrm{LH} ; \mathrm{D})$ contents in 6-15-month-old male and female WT $(n=6)$ and PWS-ICdel $(n=6$ (male) and 5 (female)) littermate mice. Data shown are mean \pm S.E.M., with statistical comparisons performed by 1 -way ANOVA and Bonferroni post hoc test $(* P<0.05 ; * * P<0.01 ; * \star * P<0.001 ; * * * * P<0.0001$ vs WT littermates (same sex); ${ }^{\dagger \dagger} P<0.01 ;{ }^{+t \dagger} P<0.0001$ vs male littermates (same genotype)). 
A Pituitary Weight
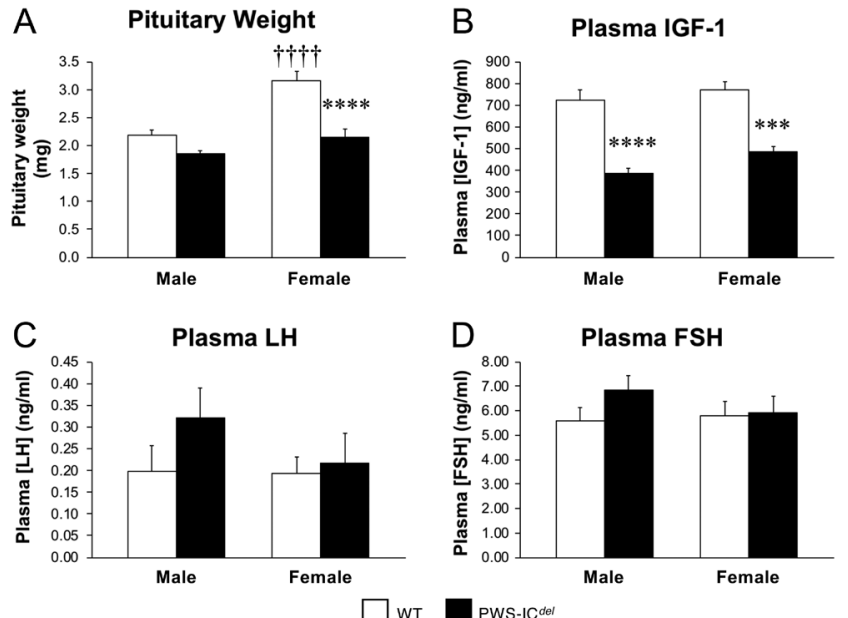

Figure 5

PWS-ICdel mice show reduced GH-IGF-1 axis activity. Quantification of pituitary weight (A) and plasma insulin-like growth factor-1 (IGF-1; B), luteinising hormone $(\mathrm{LH} ; \mathrm{C})$ and follicle-stimulating hormone $(\mathrm{FSH} ; \mathrm{D})$ in 5-9-month-old male and female WT and PWS-ICdel ( $n=6$ per group) littermate mice. Data shown are mean \pm s.E.M., with statistical comparisons performed by 1-way ANOVA and Bonferroni post hoc test (A and B) or Kruskal-Wallis test ( $C$ and $D)(* * * P<0.001 ; * * * * P<0.0001$ vs WT littermates (same sex); ${ }^{\dagger+t \dagger} P<0.0001$ vs male littermates (same genotype)).

significant effect on tibial marrow adiposity (Fig. 6C) or adipocyte size in either WT or PWS-ICdel males (Fig. 6E). Parallel results were also obtained in females (data not shown). Analysis of the adipocyte size profile revealed that while differences were seen between PWS-IC ${ }^{\text {del }}$ males and their WT littermates at room temperature (e.g. there were less adipocytes in the size range 525-572 $\mu^{2}$ in PWS-ICdel mice (Fig. 6F; $P=0.038)$ ), these differences were abolished in mice maintained at thermoneutrality (Fig. 6G).

As above, femoral length and cortical diameter were reduced by 8 and $25 \%$ in male PWS-IC ${ }^{\text {del }}$ mice at $20-22^{\circ} \mathrm{C}$ $(P<0.0001$; Fig. 7A and B), with average cortical wall thickness not being significantly different (Fig. 7C). None of these geometric variables were altered by increasing the ambient temperature to thermoneutrality (Fig. 7A, B and C). However, the $48 \%$ reduction in the biomechanical strength of the femoral cortex in PWS-IC ${ }^{\text {del }}$ mice at room temperature $(P<0.0001 ;$ Fig. 7D), was abolished when PWS-IC ${ }^{d e l}$ mice were maintained at thermoneutrality (Fig. 7D). This improvement in biomechanical performance was entirely due to the significant increase in the strength of the calcified tissue, UTS in PWS-ICdel mice at $30^{\circ} \mathrm{C}$ being $91 \%$ higher than that in WT littermates at thermoneutrality $(P<0.01$; Fig. 7E). In the absence of any significant effect of thermoneutrality on femoral geometry, there was no change in the geometric contribution to strength, which remained at 32\% of that in WT mice (Fig. 7F). Similar results were obtained in females, the impaired biomechanical strength in PWS-IC del mice at $20-22^{\circ} \mathrm{C}$ $(P=0.007)$, being ameliorated at thermoneutrality $(P=0.215)$, as a consequence of the contribution of tissue
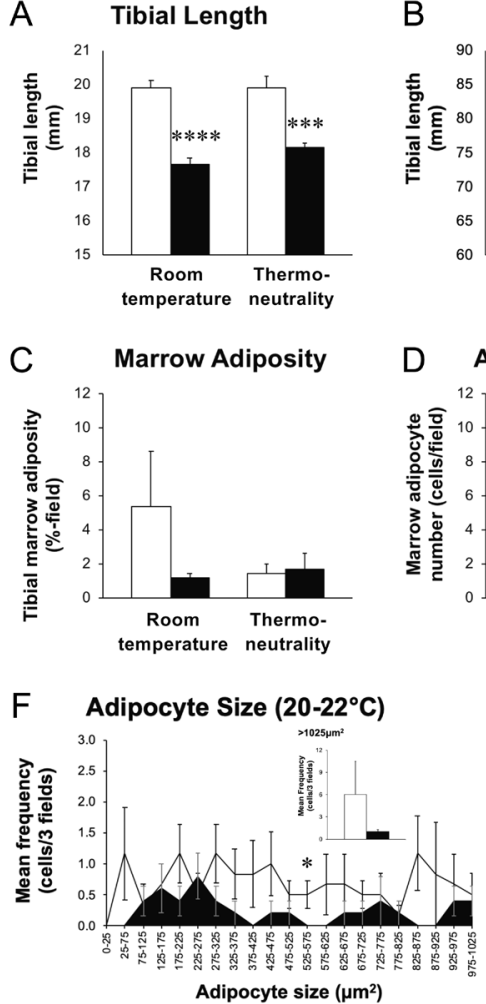
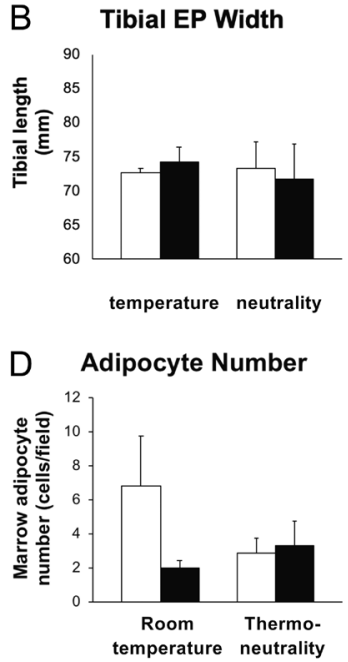

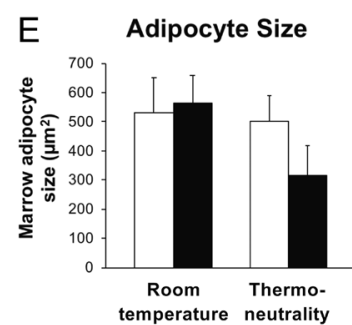

G Adipocyte Size $\left(30^{\circ} \mathrm{C}\right)$

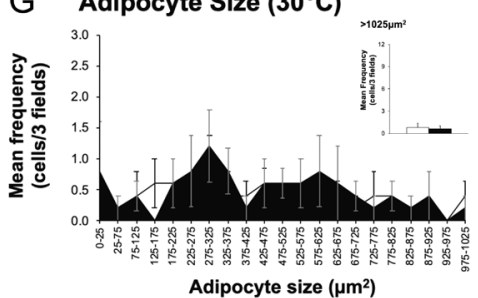

\section{Figure 6}

Thermoneutrality has little effect on growth and marrow adiposity in PWS-ICdel mice. Tibial length $(A)$, epiphyseal plate (EP) width (B), marrow adiposity (C), marrow adipocyte number (D) and mean adipocyte size $(E)$ were quantified in 6-15-month-old male WT and PWS-ICdel littermate mice after being maintained at either standard ambient temperature $\left(20-22^{\circ} \mathrm{C}\right)$ or thermoneutrality $\left(30^{\circ} \mathrm{C}\right)$ for 9 weeks. Adipocyte size profiles are presented for standard ambient temperature (F) and thermoneutrality (G). Data shown are mean \pm s.E.M. $(n=6$ (room temperature) and 5 (thermoneutrality)), with statistical comparisons performed by 1-way ANOVA and Bonferroni post hoc test $(\mathrm{A}-\mathrm{E} ; * * \star * P<0.0001$ vs room temperature (same genotype)) or unpaired Student's $t$-test ( $F$ and $\mathrm{G}$; $* P<0.05$ vs WT littermates (same temperature)). 

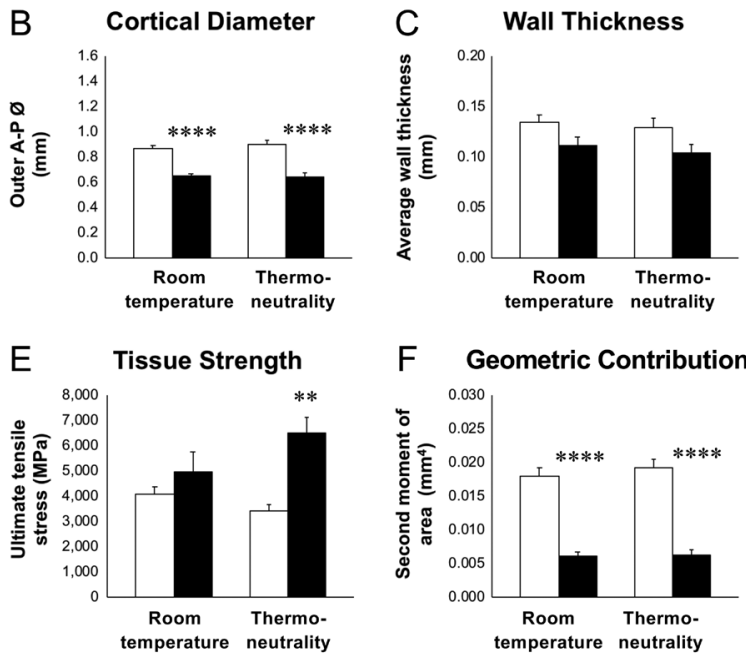

\section{Figure 7}

Thermoneutrality alleviates impaired femoral strength in PWS-ICdel mice. Femoral length (A), cortical anterior-posterior diameter (A-P Ø; B), average cortical wall thickness (C), cortical strength (ultimate moment; D), tissue strength (ultimate tensile stress; E) and the geometric contribution to strength (second moment of area; F) were quantified in 6-15-month-old male WT and PWS-ICdel after being maintained at either standard ambient temperature $\left(20-22^{\circ} \mathrm{C}\right)$ or thermoneutrality $\left(30^{\circ} \mathrm{C}\right)$ for 9 weeks $(n=6$ (room temperature) and 5 (thermoneutrality)). Data shown are mean \pm S.E.M., with statistical comparisons performed by 1-way ANOVA and Bonferroni post hoc test ( $* * P<0.01$;

$\star \star \star \star \star P<0.0001$ vs WT littermates (same ambient temperature)). strength, the impaired geometric contribution being exacerbated $(P=0.006)$ (data not shown).

\section{Discussion}

Loss of gene expression from the paternal allele of chromosome 15q11-q13 results in the marked disturbances in neural development, hormone secretion and metabolic homeostasis that characterise PWS. However, despite impaired GH secretion and GH replacement long being considered a key feature of this condition and an important element in therapeutic strategy (Lee et al. 1987, Deal et al. 2013, Carias \& Wevrick 2019), our understanding of the significance of GH deficiency for skeletal growth and integrity in the preclinical animal models of PWS is surprisingly superficial. To address this gap in our knowledge, we have analysed the phenotype of the weight-bearing long bones of the PWS-IC ${ }^{d e l}$ mouse model for 'full' PWS, shedding new light on the mechanisms of fracture risk in this complex condition.

Three prominent features of the observed skeletal phenotype deserve comment: impaired morphometric growth, impaired marrow adiposity and impaired biomechanical strength.

Preliminary evidence of growth retardation has been reported in most of the murine models for PWS, including mice with uniparental disomy (Cattanach et al. 1992) and deletions of Snrpn-Ube3a (Tsai et al. 1999a), Snurf/Snrpn exon 2 (Tsai et al. 1999b), Snord116 (Ding et al. 2008) and Magel2 (Bischof et al. 2007, Baraghithy et al. 2019), with Necdindel mice showing normal growth (Tsai et al. 1999a). However, initial attempts to quantify skeletal growth following IC deletion, in which expression of all the genes in the PWS locus is lost, have been hampered by high neonatal mortality (Yang et al. 1998). Having developed a breeding strategy to partially overcome this problem, we now report that PWS-IC ${ }^{\text {del }}$ mice display consistent shortening of appendicular bones.

This growth impairment is most likely to result from the marked deficiency in the GH-IGF-1 axis (40-50\% reductions in both pituitary GH content and circulating IGF-1). Although we cannot exclude a potential reduction in GH sensitivity, it is evident from comparison with other murine models for isolated GH deficiency (GH-D) or reduced GH signalling that the degree of growth retardation in mice appears to reflect the severity of axis inactivation, with complete loss of GH secretion/signalling producing the most severe phenotype (20-25\% reduction in body length; Zhou et al. 1997, Alba \& Salvatori 2004, Stevenson et al. 2009).

It is important to note, however, that femoral diameter (reduced by $32 \%$ in PWS-ICdel mice) was more profoundly affected than longitudinal growth. This occurred without affecting cortical wall thickness. Although broadly similar findings in mice with reduced GH signalling (Stevenson et al. 2009) suggest that loss of GH activity may be an important determinant, the fact that cortical diameter is only reduced by $17 \%$ in the complete absence of $\mathrm{GH}$ receptors implies that other factors in the PWS endotype may contribute to this diminution of diameter.

While GH deficiency may be the most likely cause, we cannot exclude the potentially negative influence of gonadotropin deficiency on bone formation (Yarram et al. 2003). In contrast, the observed PRL deficiency is unlikely to represent a significant factor in this context as PRL has been shown to inhibit osteoblast function 
(Cross et al. 2000). However, given the growing evidence for impaired oxytocin signalling in mouse models for PWS (Schaller et al. 2010), further analysis should investigate the potentially negative impact of oxytocin loss on the skeletal phenotype (Elabd et al. 2008).

A potential physical mechanism relates to the marked reduction in body weight (reduced by $40 \%$ ) and adiposity (individual fat pad weights reduced by 67-84\%) seen in PWS-ICdel mice (Golding et al. 2017). This leanness has a number of consequences. Firstly, the loading forces being applied to these weight-bearing bones are significantly reduced. These forces promote the remodelling of the bone to enhance diameter and weight-bearing capacity (David et al. 2007, Luu et al. 2009). Although muscle mass was not quantified in the current study, muscle hypoplasia in the Magel2 ${ }^{\text {del }}$ mouse model for PWS/Schaaf-Yang syndrome (SYS) (Kamaludin et al. 2016), indicates that this could represent a possible transduction mechanism. Secondly, such profound reductions in abdominal fat mass are likely to cause a dramatic reduction in circulating leptin. Any effect of hypoleptinaemia is likely to be enhanced by changes in the marrow milieu resulting from the equally dramatic reduction in marrow adiposity in this model.

This marked decline in tibial marrow adiposity is due to reductions in both marrow adipocyte number and size. While the latter parallels the changes we previously reported in intra-abdominal white adipose tissue (Golding et al. 2017), our current data indicate that in the bone marrow at least, impaired adipogenesis is also a significant factor. In the context of the barrage of endocrine signals promoting marrow adiposity, this is quite remarkable. For example, $d w / d w$ rats, which show a similar degree of GH-D accompanied by intra-abdominal leanness, show elevated marrow adiposity (mainly increased adipogenesis) (Gevers et al. 2002), with GH treatment inhibiting adipogenesis and triglyceride storage (Gevers et al. 2002). In addition, since ghrelin is powerfully adipogenic in bone marrow (Thompson et al. 2004, Davies et al. 2009, Hopkins et al. 2017), the marked hyperghrelinaemia in PWS-IC ${ }^{d e l}$ mice (Golding et al. 2017) should elevate marrow adiposity. Clearly, the anti-adipogenic signals in PWS-ICdel mice are more than sufficient to reverse these influences. The absence of the larger adipocytes in bone marrow corresponds with the reported impairment of lipid storage capacity in intra-abdominal WAT in these mice (Golding et al. 2017) and the impairment of lipid storage in cultured adipocytes from humans with PWS (Cadoudal et al. 2014). Whether the obesity that usually accompanies PWS in humans leads to parallel changes in marrow adiposity remains to be established.
With this degree of leanness in the marrow, it is highly likely that the production of leptin from marrow adipocytes (Laharrague et al. 1998) is reduced in parallel. Interestingly, intra-bone marrow infusion of leptin in GH-D rats not only halves marrow adiposity by suppressing adipogenesis, but increases osteoblast surface (Evans et al. 2011). Given this role of leptin in maintaining the bone microenvironment, one would expect bones from PWS-ICdel mice to show evidence of elevated osteoblast activity. However, while the function of PWS-ICdel osteoblasts should be examined in vitro, our data indicate that osteoblast activity does not appear to be enhanced in vivo. Indeed, the combination of unaltered relative trabecular surface, a more fragmented trabecular lattice and an unchanged osteoclast density, imply that PWS-ICdel osteoblast number and/or activity is reduced. The combined reduction in adipocytes and osteoblasts is unusual and suggests a failure in the proliferation of MSCs or their subsequent differentiation.

In the context of this endocrine and cellular milieu, the biomechanical integrity of the femoral cortex is clearly compromised. Surprisingly, UTS, a measure of the strength of the calcified tissue, per se, is significantly increased. Such increases in tissue strength usually result from a greater density of either matrix proteins or hydroxyapatite. This is likely to be due to the reduction in GH axis activity, producing slower growing and less remodelled bone (Locatelli \& Bianchi 2014). Nevertheless, despite this increased tissue strength, the geometric component of strength (second moment of area) is profoundly reduced, which corresponds directly with the smaller cortical diameter discussed earlier. Indeed, the impairment of this geometric component is more than sufficient to translate an elevated UTS into a compromised overall organ strength.

While the analysis of single gene deletion models in this context is far from complete, the information available suggests some potential genetic mechanisms underlying the complex skeletal phenotype observed. The impairment of the GH axis may be due in part to the loss of expression of Snord116, because although Snord116 ${ }^{\text {del }}$ mice show normal pituitary volume, somatotroph number (Ding et al. 2008) and GH content (Burnett et al. 2017), circulating IGF-1 is reduced by $60-70 \%$ (Ding et al. 2008, Qi et al. 2016). This lack of GH action, possibly as the result of impaired activity of the hormone pro-convertase enzyme PC1 (Burnett et al. 2017) increases GH-releasing hormone mRNA expression in the arcuate nucleus (Qi et al. 2016) reflecting impaired GH feedback. In contrast, male Magel2 ${ }^{\text {del }}$ mice show normal IGF-1 levels, with IGF-1 secretion and ghrelin-induced 
(but not GHRH-induced) GH responses impaired in female mice (Tennese \& Wevrick 2011). However, given the episodic nature of GH secretion in rodents, establishing the relationship between these specific genes and the parameters of spontaneous GH secretion would be more readily achieved in a larger species.

In the context of skeletal growth, body length is only modestly reduced in Snord $116^{\mathrm{del}}$ mice, with a $10 \%$ reduction in bone mineral density (Ding et al. 2008, Qi et al. 2016). Although overall body length is normal in the absence of Magel2 (Bischof et al. 2007), femoral length, cortical diameter and cortical wall thickness are reduced in female Magel2 ${ }^{\text {del }}$ mice by 9-13\% (Baraghithy et al. 2019). Indeed, this is the only model in which a comprehensive analysis has been made of the skeletal phenotype. Interestingly, although these mice also show comparable reductions in trabecular number, trabecular fragmentation, femoral strength and UTS to that reported here in the PWS-IC ${ }^{\text {del }}$ mice, marrow adiposity is more than doubled (Baraghithy et al. 2019) compared to the profound reduction reported here. This implies that loss of one of the other genes in the PWS locus either disrupts the relationship between adipocyte and osteoblast differentiation, or the proliferation of MSCs. Since Necdin has already been identified as a regulator of astrocyte (Fujimoto et al. 2016), neocortical neural precursor cell (Minamide et al. 2014), haematopoietic stem cell (Asai et al. 2012) and pre-adipocyte (Fujiwara et al. 2012) differentiation, this seems like a potential candidate.

Given that the normal relationship between fat mass and bone remodelling is disrupted in PWS-IC ${ }^{d e l}$ mice, and our previous evidence that raising ambient temperature suppresses brown adipose tissue function (Golding et al. 2017), we investigated the effects of maintaining PWS$\mathrm{IC}^{\mathrm{del}}$ mice at thermoneutrality on this altered skeletal phenotype. While this manipulation had no effect on marrow adiposity, there was a significant improvement in biomechanical strength as a result of an increased strength of the calcified tissue. This is remarkable since we have previously shown that this manipulation halved food intake in PWS-IC ${ }^{d e l}$ mice (Golding et al. 2017). When coupled with evidence that thermoneutrality normalises skeletal length and bone mineral density in Snord116 del mice (Qi et al. 2017), this implies that bone turnover is dramatically reduced at thermoneutrality. This interpretation is supported by evidence that thermoneutrality increases bone formation and reduces bone resorption in growing female $\mathrm{C} 57 \mathrm{BL} / 6 \mathrm{~J}$ mice, while dramatically reducing food intake and doubling marrow adiposity (Iwaniec et al. 2016). The latter observation serves to re-emphasise the likely impairment of adipocyte function in the PWS-ICdel model (Golding et al. 2017).

In summary, our data show that the longitudinal growth and biomechanical integrity of long bones are markedly impaired in the PWS-IC ${ }^{\text {del }}$ mouse model for 'full' PWS. Whether this impairment is matched by deficits in the biomechanical properties of other types of bone, for example calvarial or vertebral bone, is yet to be established, but our data not only provide a biomechanical basis for the increased fracture risk in PWS (Butler et al. 2002, Longhi et al. 2015), but indicate that thermoneutrality may be beneficial in this context. The final phenotype observed in the PWS-IC ${ }^{\text {del }}$ mice appears to result from the combined loss of several genes from within the PWS locus, but a more precise genetic cause for the individual aspects remains to be fully elucidated.

\section{Declaration of interest}

The authors declare that there is no conflict of interest that could be perceived as prejudicing the impartiality of the research reported.

\section{Funding}

This work was supported by a summer studentship awarded by the Foundation for Prader-Willi Research (to T M B, B E K and T W). A G and $P$ M were supported by grants from the Agence Nationale de la Recherche (ANR-15-CE14-0012-01, ANR-18-C14-0017-01), Institut National de la Santé et de la Recherche Médicale, Centre National de la Recherche Scientifique, and Université de Montpellier.

\section{Acknowledgements}

The authors thank JBIOS staff and Derek Scarborough (Cardiff University) for excellent technical support.

\section{References}

Alba M \& Salvatori R 2004 A mouse with targeted ablation of the growth hormone-releasing hormone gene: a new model of isolated growth hormone deficiency. Endocrinology 145 4134-4143. (https://doi. org/10.1210/en.2004-0119)

Asai T, Liu Y, Di Giandomenico S, Bae N, Ndiaye-Lobry D, Deblasio A, Menendez S, Antipin Y, Reva B, Wevrick R, et al. 2012 Necdin, a P53 target gene, regulates the quiescence and response to genotoxic stress if hematopoietic stem/progenitor cells. Blood 120 1601-1612. (https://doi.org/10.1182/blood-2011-11-393983)

Baraghithy S, Smoum R, Drori A, Hdar R, Gammal A, Hirsch S, AttarNamdar M, Nemirovski A, Gabet Y, Langer Y, et al. 2019 Magel2 modulates bone remodelling and mass in Prader-Willi syndrome by affecting oleoyl serine levels and activity. Journal of Bone and Mineral Research 34 93-105. (https://doi.org/10.1002/jbmr.3591)

Beresford JN, Bennett JH, Devlin C, Leboy PS \& Owen ME 1992 Evidence for an inverse relationship between the differentiation of adipocytic 
and osteogenic cells in rat marrow stromal cell cultures. Journal of Cell Science 102 341-351.

Bischof JM, Stewart CL \& Wevrick R 2007 Inactivation of the mouse Magel 2 gene results in growth abnormalities similar to Prader-Willi syndrome. Human Molecular Genetics 16 2713-2719. (https://doi. org/10.1093/hmg/ddm225)

Bouxsein ML, Boyd SK, Christiansen BA, Guldberg RE, Jepsen KJ \& Müller R 2010 Guidelines for assessment of bone microarchitecture in rodents using micro-computed tomography. Journal of Bone and Mineral Research 25 1468-1486. (https://doi.org/10.1002/jbmr.141)

Burnett LC, LeDuc CA, Sulsona CR, Paul D, Rausch R, Eddiry S, Martin Carli JF, Morabito MV, Skowronski AA, Hubner G, et al. 2017 Deficiency in prohormone convertase PC1 impairs prohormone processing in Prader-Willi syndrome. Journal of Clinical Investigation 127 293-305. (https://doi.org/10.1172/JCI88648)

Butler JV, Whittington JE, Holland AJ, Boer H, Clarke D \& Webb T 2002 Prevalence of, and risk factors for, physical ill-health in people with Prader-Willi syndrome: a population-based study. Developmental Medicine and Child Neurology 44 248-255. (https://doi.org/10.1017/ S001216220100202X)

Butler MG, Manzardo AM \& Forster JL 2016 Prader-Willi syndrome: clinical genetics and diagnostic aspects with treatment approaches. Current Pediatric Reviews 12 136-166. (https://doi.org/10.2174/157339 6312666151123115250)

Cadoudal T, Buléon M, Segenès C, Diene G, Desneulin F, Molinas C, Eddiry S, Conte-Auriol F, Daviaud D, Martin PG, et al. 2014 Impairment of adipose tissue in Prader-Willi syndrome rescued by growth hormone treatment. International Journal of Obesity $\mathbf{3 8}$ 1234-1240. (https://doi.org/10.1038/ijo.2014.3)

Carias KV \& Wevrick R 2019 Preclinical testing in translational animal models of Prader-Willi syndrome: overview and gap analysis. Molecular Therapy: Methods and Clinical Development 13 344-358. (https://doi.org/10.1016/j.omtm.2019.03.001)

Cattanach BM, Barr JA, Evans EP, Burtenshaw M, Beechey CV, Leff SE, Brannan CI, Copeland NG, Jenkins NA \& Jones J 1992 A candidate mouse model for Prader-Willi syndrome which shows an absence of Snrpn expression. Nature Genetics 2 270-274. (https://doi. org/10.1038/ng1292-270)

Chamberlain SJ, Johnstone KA, DuBose AJ, Simon TA, Bartolomei MS, Resnick JL \& Brannan CI 2004 Evidence for genetic modifiers of postnatal lethality in PWS-IC deletion mice. Human Molecular Genetics 13 2971-2977. (https://doi.org/10.1093/hmg/ddh314)

Cross D, Yang L, Kuo CB, Xu X, Luben RA \& Walker AM 2000 Effects of prolactin on osteoblast alkaline phosphatase and bone formation in the developing rat. American Journal of Physiology: Endocrinology and Metabolism 279 E1216-E1225. (https://doi.org/10.1152/ ajpendo.2000.279.6.E1216)

Cummings DE, Clement K, Purnell JQ, Vaisse C, Foster KE, Frayo RS, Schwartz MW, Basdevant A \& Weigle DS 2002 Elevated plasma ghrelin levels in Prader-Willi syndrome. Nature Medicine 8 643-644. (https://doi.org/10.1038/nm0702-643)

David V, Martin A, Lafage-Proust MH, Malaval L, Peyroche S, Jones DB, Vico L \& Guignandon A 2007 Mechanical loading down-regulates peroxisome proliferator-activated receptor $\gamma$ in bone marrow stromal cells and favours osteoblastogenesis at the expense of adipogenesis. Endocrinology 148 2553-2562. (https://doi.org/10.1210/en.2006-1704)

Davies JS, Kotokorpi P, Eccles SR, Barnes SK, Tokarczuk PF, Allen SK, Whitworth HS, Guschina IA, Evans BA, Mode A, et al. 2009 Ghrelin induces abdominal obesity via GHS-R-dependent lipid retention. Molecular Endocrinology 23 914-924. (https://doi.org/10.1210/ me.2008-0432)

Deal CL, Tony M, Höybye C, Allen DB, Tauber M, Christiansen JS \& 2011 Growth Hormone in Prader-Willi Syndrome Clinical Care Guidelines Workshop Participants 2013 Growth Hormone Research Society Workshop Summary: consensus guidelines for recombinant human growth hormone therapy in Prader-Willi syndrome. Journal of
Clinical Endocrinology and Metabolism 98 E1072-E1087. (https://doi. org/10.1210/jc.2012-3888)

Di Iorgi N, Rosol M, Mittelman SD \& Gilsanz V 2008 Reciprocal relation between marrow adiposity and the amount of bone in the axial and appendicular skeleton of young adults. Journal of Clinical Endocrinology and Metabolism 93 2281-2286. (https://doi.org/10.1210/jc.2007-2691)

Ding F, Li HH, Zhang S, Solomon NM, Camper SA, Cohen P \& Franke U 2008 SnoRNA Snord116 (Pwcr/MBII-85) deletion causes growth deficiency and hyperphagia in mice. PLOS ONE 3 e1709. (https://doi. org/10.1371/journal.pone.0001709)

Elabd C, Basillais A, Beaupied H, Breuil V, Wagner N, Scheideler M, Zaragosi LE, Massiéra F, Lemichez E, Trajanoski Z, et al. 2008 Oxytocin controls differentiation of human mesenchymal stem cells and reverses osteoporosis. Stem Cells 26 2399-2407. (https://doi. org/10.1634/stemcells.2008-0127)

Evans BAJ, Bull MJ, Kench RC, Fox RE, Morgan LD, Stevenson AE, Gevers EF, Perry MJ \& Wells T 2011 The influence of leptin on trabecular architecture and marrow adiposity in GH-deficient rats. Journal of Endocrinology 208 69-79. (https://doi.org/10.1677/JOE-100178)

Fujimoto I, Hasegawa K, Fujiwara K, Yamada M \& Yoshikawa K 2016 Necdin controls EGFR signalling linked to astrocyte differentiation in primary cortical progenitor cells. Cellular Signalling 28 94-107. (https://doi.org/10.1016/j.cellsig.2015.11.016)

Fujiwara K, Hasegwa K, Ohkumo T, Miyoshi H, Tseng YH \& Yoshikawa K 2012 Necdin controls proliferation of white adipose progenitor cells. PLOS ONE 7 e30948. (https://doi.org/10.1371/journal.pone.0030948)

Gevers EF, Loveridge N \& Robinson IC 2002 Bone marrow adipocytes: a neglected target tissue for growth hormone. Endocrinology 143 4065-4073. (https://doi.org/10.1210/en.2002-220428)

Golding DM, Rees DJ, Davies JR, Relkovic D, Furby HV, Guschina IA, Hopkins AL, Davies JS, Resnick JL, Isles AR, et al. 2017 Paradoxical leanness in the imprinting-centre deletion mouse model for PraderWilli syndrome. Journal of Endocrinology 232 123-135. (https://doi. org/10.1530/JOE-16-0367)

Grosso S, Cioni M, Buoni S, Peruzzi L, Pucci L \& Berardi R 1998 Growth hormone secretion in Prader-Willi syndrome. Journal of Endocrinological Investigation 21 418-422. (https://doi.org/10.1007/ BF03347319)

Guillou A, Romanò N, Steyn F, Abitbol K, Le Tissier P, Bonnefont X, Chen C, Mollard P \& Martin AO 2015 Assessment of lactotroph axis functionality in mice: longitudinal monitoring of PRL secretion by ultrasensitive-ELISA. Endocrinology 156 1924-1930. (https://doi. org/10.1210/en.2014-1571)

Hamrick MW, Della-Fera MA, Choi YH, Pennington C, Hartzell D $\&$ Baile CA 2005 Leptin treatment induces loss of bone marrow adipocytes and increases bone formation in leptin-deficient $o b / o b$ mice. Journal of Bone and Mineral Research 20 994-1001. (https://doi. org/10.1359/JBMR.050103)

Hopkins AL, Nelson TAS, Guschina IA, Parsons LC, Lewis CL, Brown RC, Christian HC, Davies JS \& Wells T 2017 Unacylated ghrelin promotes adipogenesis in rodent bone marrow via ghrelin $\mathrm{O}$-acyl transferase and GHS- $\mathrm{R}_{1 \mathrm{a}}$ activity: evidence for target cell-mediated acylation. Scientific Reports 7 45541. (https://doi.org/10.1038/srep45541)

Iwaniec UT, Philbrick KA, Wong CP, Gordon JL, Kahler-Quesada AM, Olson DA, Branscum AJ, Sargent JL, DeMambro VE, Rosen CJ, et al. 2016 Room temperature housing results in premature cancellous bone loss in growing female mice: implications for the mouse as a preclinical model for age-related bone loss. Osteoporosis International 27 3091-3101. (https://doi.org/10.1007/s00198-016-3634-3)

Kahn MJ, Gerasimidis K, Edwards CA \& Shaikh MG 2018 Mechanisms of obesity in Prader-Willi syndrome. Pediatric Obesity 13 3-13. (https:// doi.org/10.1111/ijpo.12177)

Kamaludin AA, Smolarchuk C, Bischof JM, Eggert R, Greer JJ, Ren J, Lee JJ, Yokota T, Berry FB \& Wevrick R 2016 Muscle dysfunction caused by loss of Magel2 in a mouse model of Prader-Willi and Schaaf-Yang https://joe.bioscientifica.com

https://doi.org/10.1530/JOE-19-0279 (c) 2019 Society for Endocrinology Published by Bioscientifica Ltd.
Printed in Great Britain 
syndromes. Human Molecular Genetics 25 3798-3809. (https://doi. org/10.1093/hmg/ddw225)

Khor EC, Fanshawe B, Qi Y, Zolotukhin S, Kulkarni RN, Enriquez RF, Purtell L, Lee NJ, Wee NK, Croucher PI, et al. 2016 Prader-Willi critical region, a non-translated, imprinted central regulator of bone mass: possible role in skeletal abnormalities on Prader-Willi syndrome. PLoS ONE 11 e0148155. (https://doi.org/10.1371/journal.pone.0148155)

Laharrague P, Larrouy D, Fontanilles AM, Truel N, Campfield A, Tenenbaum R, Galitzky J, Corberand JX, Pénicaud L \& Casteilla L 1998 High expression of leptin by human bone marrow adipocytes in primary culture. FASEB Journal 12 747-752. (https://doi.org/10.1096/ fasebj.12.9.747)

Lee PD, Wilson DM, Rountree L, Hintz RL \& Rosenfeld RG 1987 Linear growth response to exogenous growth hormone in Prader-Willi syndrome. American Journal of Medical Genetics 28 865-871. (https:// doi.org/10.1002/ajmg.1320280411)

Leiben L, Callewaert F \& Bouillon R 2009 Bone and metabolism: a complex crosstalk. Hormone Research 71 (Supplement 1) 134-138. (https://doi.org/10.1159/000178056)

Locatelli V \& Bianchi VE 2014 Effect of GH/IGF-1 on bone metabolism and osteoporosis. International Journal of Endocrinology 2014235060. (https://doi.org/10.1155/2014/235060)

Longhi S, Grugni G, Gatti D, Spinnozzi E, Sartorio A, Adami S, Fanolla A \& Radetti G 2015 Adults with Prader-Willi syndrome have weaker bones: effect of treatment with GH and sex steroids. Calcified Tissue International 96 160-166. (https://doi.org/10.1007/s00223-014-9949-1)

Luu YK, Capilla E, Rosen CJ, Gilsanz V, Pessin JE, Judex S \& Rubin CT 2009 Mechanical stimulation of mesenchymal stem cell proliferation and differentiation promotes osteogenesis while preventing dietaryinduced obesity. Journal of Bone and Mineral Research 24 50-61. (https://doi.org/10.1359/JBMR.080817)

Miller JL, Lynn CH, Driscoll DC, Goldstone AP, Gold JA, Kimonis V, Dykens E, Butler MG, Shuster JJ \& Driscoll DJ 2011 Nutritional phases in Prader-Willi syndrome. American Journal of Medical Genetics: Part A 155A 1040-1049. (https://doi.org/10.1002/ajmg.a.33951)

Minamide R, Fujiwara K, Hasegawa K \& Yoshikawa K 2014 Antagonistic interplay between necdin and Bmi1 controls proliferation of neural precursor cells in the embryonic mouse neocortex. PLOS ONE 9 e84460. (https://doi.org/10.1371/journal.pone.0084460)

Muscatelli F, Abrous DN, Massacrier A, Boccaccio I, Le Moal M, Cau P \& Cremer H 2000 Disruption of the mouse necdin gene results in hypothalamic and behavioural alterations reminiscent of the human Prader-Willi syndrome. Human Molecular Genetics 9 3101-3110. (https://doi.org/10.1093/hmg/9.20.3101)

Navein AE, Cooke EJ, Davies JR, Smith TG, Wells LHM, Ohazama A, Healy C, Sharpe PT, Evans SL, Evans BAJ, et al. 2016 Disrupted mitochondrial function in the Opa3 ${ }^{\mathrm{L} 122 \mathrm{P}}$ mouse model for Costeff syndrome impairs skeletal integrity. Human Molecular Genetics 25 2404-2416. (https://doi.org/10.1093/hmg/ddw107)

Pravdivyi I, Ballanyi K, Colmers WF \& Wevrick R 2015 Progressive postnatal decline in leptin sensitivity of arcuate hypothalamic neurons in the Magel2-null mouse model of Prader-Willi syndrome. Human Molecular Genetics 24 4276-4283. (https://doi.org/10.1093/ hmg/ddv159)

Qi Y, Purtell L, Fu M, Lee NJ, Aepler J, Zhang L, Loh K, Enriquez RF, Baldock PA, Zolotukhin S, et al. 2016 Snord116 is critical in the regulation of food intake and body weight. Scientific Reports 618614. (https://doi.org/10.1038/srep18614)

Qi Y, Purtell L, Fu M, Sengmany K, Loh K, Zhang L, Zolotukhin S, Sainsbury A, Campbell L \& Herzog H 2017 Ambient temperature modulates the effects of the Prader-Willi syndrome candidate gene
Snord116 on energy homeostasis. Neuropeptides 61 87-93. (https:// doi.org/10.1016/j.npep.2016.10.006)

Schaller F, Watrin F, Sturny R, Massacrier A, Szepetowski P \& Muscatelli F 2010 A single postnatal injection of oxytocin rescues the lethal feeding behaviour in mouse newborns deficient for the imprinted Magel2 gene. Human Molecular Genetics 19 4895-4905. (https://doi. org/10.1093/hmg/ddq424)

Stevenson AE, Evans BA, Gevers EF, Elford C, McLeod RW, Perry MJ, El-Kasti MM, Coschigano KT, Kopchick JJ, Evans SL, et al. 2009 Does adiposity status influence femoral cortical strength in rodent models of growth hormone deficiency? American Journal of Physiology: Endocrinology and Metabolism 296 E147-E156. (https://doi. org/10.1152/ajpendo.90689.2008)

Steyn FJ, Huang L, Ngo ST, Leong JW, Tan HY, Xie TY, Parlow AF, Veldhuis JD, Waters MJ \& Chen C 2011 Development of a method for the determination of pulsatile growth hormone secretion in mice. Endocrinology 152 3165-3171. (https://doi.org/10.1210/en.2011-0253)

Steyn FJ, Wan Y, Clarkson J, Veldhuis JD, Herbison AE \& Chen C 2013 Development of a methodology for and assessment of pulsatile luteinizing hormone secretion in juvenile and adult male mice. Endocrinology 154 4939-4945. (https://doi.org/10.1210/en.2013-1502)

Tennese AA \& Wevrick R 2011 Impaired hypothalamic regulation of endocrine function and delayed counterregulatory response to hypoglycaemia in Magel2-null mice. Endocrinology 152 967-978. (https://doi.org/10.1210/en.2010-0709)

Thomas T, Gori F, Khosla S, Jensen MD, Burguera B \& Riggs BL 1999 Leptin acts on human marrow stromal cells to enhance differentiation to osteoblasts and to inhibit differentiation to adipocytes. Endocrinology 140 1630-1638. (https://doi.org/10.1210/endo.140.4.6637)

Thompson NM, Gill DAS, Davies R, Loveridge N, Houston PA, Robinson ICAF \& Wells T 2004 Ghrelin and des-octanoyl ghrelin promote adipogenesis directly in vivo by a mechanism independent of the type 1a growth hormone secretagogue receptor. Endocrinology 145 234-242. (https://doi.org/10.1210/en.2003-0899)

Tilston TW, Brown RD, Wateridge MJ, Arms-Williams B, Walker JJ, Sun Y \& Wells T 2019 A novel automated system yields reproducible temporal feeding patterns in laboratory rodents. Journal of Nutrition 149 1674-1684. (https://doi.org/10.1093/jn/nxz116)

Tsai TF, Armstrong D \& Beaudet AL 1999a Necdin-deficient mice do not show lethality or the obesity and infertility of Prader-Willi syndrome. Nature Genetics 22 15-16. (https://doi.org/10.1038/8722)

Tsai TF, Jiang YH, Bressler J, Armstrong D \& Beaudet AL 1999b Paternal deletion from Snrpn to Ube3a in the mouse causes hypotonia, growth retardation and partial lethality and provides evidence for a gene contributing to Prader-Willi syndrome. Human Molecular Genetics 8 1357-1364. (https://doi.org/10.1093/hmg/8.8.1357)

Yang T, Adamson TE, Resnick JL, Leff S, Wevrick R, Franke U, Jenkins NA, Copeland NG \& Brannan CI 1998 A mouse model for Prader-Willi syndrome imprinting-centre mutations. Nature Genetics 19 25-31. (https://doi.org/10.1038/ng0598-25)

Yarram SJ, Perry MJ, Christopher TJ, Westby K, Brown NL, Lamminen T, Rulli SB, Zhang FP, Huhtaniemi I, Sandy JR, et al. 2003 Luteinizing hormone receptor knockout (LuRKO) mice and transgenic human chorionic gonadotropin (hCG)-overexpressing mice (hCG alphabeta+) have bone phenotypes. Endocrinology 144 3555-3564. (https://doi. org/10.1210/en.2003-0036)

Zhou Y, Xu BC, Maheshwari HG, He L, Reed M, Lozykowski M, Okada S, Cataldo L, Coschigamo K, Wagner TE, et al. 1997 A mammalian model for Laron syndrome produced by targeted disruption of the mouse growth hormone receptor/binding protein gene (the Laron mouse). PNAS 94 13215-13220. (https://doi.org/10.1073/pnas.94.24.13215)

Received in final form 30 July 2019

Accepted 19 August 2019

Accepted Preprint published online 20 August 2019 https://joe.bioscientifica.com https://doi.org/10.1530/JOE-19-0279 (c) 2019 Society for Endocrinology Published by Bioscientifica Ltd. Printed in Great Britain 